\title{
Research and Practice of the E-seal/E-lock system based on mobile internet
}

\author{
Xia Jiang ${ }^{\mathrm{a}}$, Shu Meng ${ }^{\mathrm{b}}$ and Qingli $\mathrm{Li}^{\mathrm{c}}$ \\ East China Normal University, Shanghai 200062, China; \\ axjiang@mail.ecnu.cn, bsmeng@fem.ecnu.edu.cn, cqlli@cs.ecnu.edu.cn
}

Keywords: E-seal, E-lock, mobile internet, APP, NFC, BLE.

\begin{abstract}
With the development of mobile internet and the smartphone, E-seal and E-lock using NFC or BLE technologies become a good choice to prevent the goods stolen or transferred so as to make the logistics safer. This paper introduces a new E-seal/E-lock system based on mobile internet in detail, including system components, the operation process and hardware structure of e-lock, system platform architecture and APP design process etc. Finally, this paper describes the system functions and applications. Combined with the smart phone, the system will have a wide range of applications.
\end{abstract}

\section{Introduction}

Logistics is the key process in global trade, military and so on. However, with the increasing complexity of logistics systems, the chance of cargo stolen is higher than ever [1]. Stealing and goods transferring are usually reported in the media in the U.S.A, European countries, as well as China, which is one of the worlds' largest logistics market. For example, for CNPC (China National Petroleum Corporation), during the transportation of its petroleum products from the oil storage to service station, the alleged loss valued a large amount of money. Also, P\&G, who holds large amount of stores in cities and towns, often find that their goods have been switched in the process of logistics. Moreover, issues like smuggling, contraband, dangerous goods, and terrorism are becoming more severe during the process [2-3].

These problems occurred because of lacking means to track and monitor container transportation. The most prominent problem has two aspects, one is to identify the authenticity and integrity of the goods. The second is, across multiple aspects of collusion and crime. So, seal and lock emerge at the moment. In the preservation of goods, there are a lot of applications concerning the application of the seal and the lock. To distinguish the differences will help us analyze the problem. See Table 1.

Table 1. The similarities and differences of Lock and Seal

\begin{tabular}{|c|c|c|}
\hline \multirow{2}{*}{ Similarities } & \multicolumn{2}{|c|}{ Differences } \\
\hline & Lock & Seal \\
\hline They are both blockade & They are both blockade & $\begin{array}{l}\text { Mainly used to indicate the result } \\
\text { of the invasions of the violence. }\end{array}$ \\
\hline \multirow[t]{2}{*}{$\begin{array}{l}\text { Mainly used to indicate } \\
\text { the result of the } \\
\text { invasions of the violence }\end{array}$} & $\begin{array}{l}\text { the key to open the lock prove the } \\
\text { uniqueness of the key and the lock }\end{array}$ & $\begin{array}{l}\text { Seal always through verify the } \\
\text { mark. }\end{array}$ \\
\hline & $\begin{array}{l}\text { Lock and unlock are the locks' two } \\
\text { operations, need to use the key, the key and } \\
\text { the lock exist the only correspondence } \\
\text { relationship. } \\
\text { Reused }\end{array}$ & $\begin{array}{l}\text { "Seal" and "unseal" are the seals' } \\
\text { two operations, need to use tools, } \\
\text { the tools and seals do not } \\
\text { correspond. } \\
\text { one-time use }\end{array}$ \\
\hline
\end{tabular}

In addition, key management exists obvious security holes, e.g. the key can easily to be copied, key distribution, and management or licensing issues cannot be solved.

The development of electronic technology gave birth to RFID e-seals and e-locks, achieving the automatic identification and safety identification [4-7]. With the rapid development of mobile Internet, the terminal's (i.e. smart phones) scale, functionality and performance change with each passing day, as well as the application and business model. Thus the e-seal / lock usher in a new 
opportunity to be combined with mobile Internet applications for the following reasons: 1) Mobile Internet intelligent terminal has been widely used with the feature of low-cost, multi-interface, and accessibility at anytime, anywhere by anyone. 2) In recent years, low-power short-range communication air interface, such as Near Field Communication (NFC) and Bluetooth Low Energy (BLE), are available to achieve interaction between terminal and e-seal / lock. Thus allows the transformation of RFID from passive "recognition" to active "link". 3) The increasing mature of micro-ultra-low-power sensor technology and positioning technology continually cut the cost down.

Due to the popularity and development of mobile smart terminals[8], the application of e-seal / lock completely get rid of the dedicated equipment for identification and communication, achieving easy operation at anytime, anywhere and by any authorized person.

There were some systems [9] and solutions [10] that employ the RFID or BLE to tags or sensors into goods transportation process. However, some of them are still under the research with the limitation in structure and application at present. Some are worked in certain closed-loop systems.[11]And the already applied systems has been proved not easy to be lay out, because of its concentration on the use of reader, tag, and the communication between them.[12] So they are still insufficient concerning convenience and realizing key-not or real-time tracking and monitoring during transportation process[13].

This paper presents an original architecture applying RFID including both NFC and BLE with certain APP aimed at tracking and monitoring with public mobile network at anywhere and in anytime.

\section{E-seal/E-lock System based on Mobile Internet}

The architecture of this system includes the platform, e-seal / lock and mobile phone APP. E-seal / lock does not contain the communication module. Operation of the safety certification and all kinds of logistics information is completed through the APP by smart phone, i.e. smart phone is the bridge to connect the system platform and e-seal / lock. At the same time, smart phones, combined with GPS module and camera, can automatically capture the information of operation time, location, photos and video and then interact with the system platform with those information.

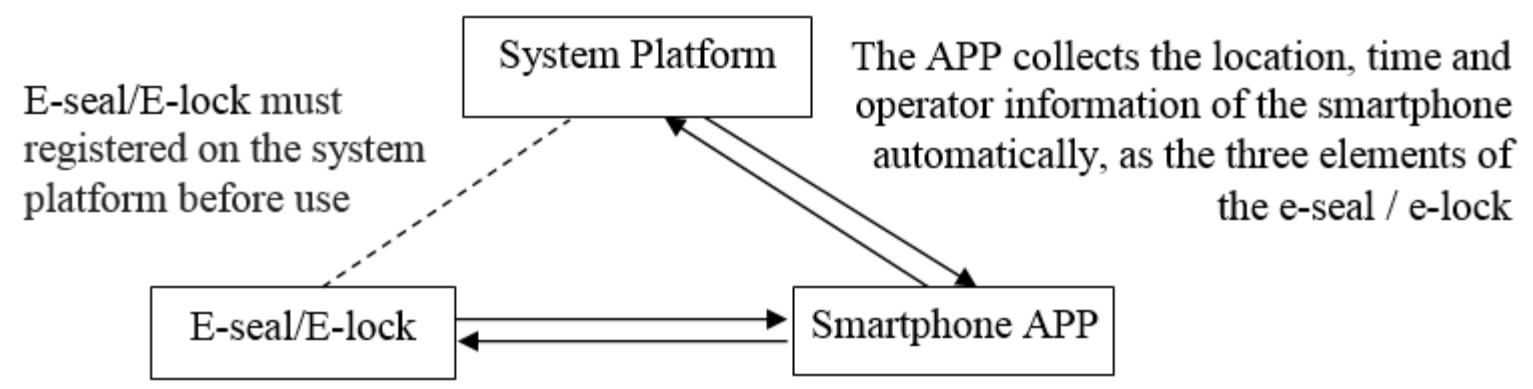

The information, including security certification and

operations, can be transmitted by smartphone between

the platform and the e-seal /e-lock

Fig. 1 System overall block diagram

A step of information gathering is added to the operating process of e-seal / lock system compare to the process of the existing mechanical seal / lock. Take the container shipment as an example, the first step is to install the e-seal / lock, then to use the smart phone to read the e-seal / lock. After the verification, lock the seal / lock through APP by smart phone, at the same time the information of operator, time, location and photograph will be automatically upload to the system platform. During the transportation, operator can inspect the e-seal / lock by smart phone, when time and location information will be automatically upload to the system platform. When transportation end, verify the e-seal / lock by the smart phone to confirm the operation of unseal/unlock, and meanwhile upload the operator, time, location, photos and other information to the platform on spot. The last step is to cut 
the e-seal and discard, or remove the e-lock for reuse. The operation of the e-seal / lock is shown in Fig2.

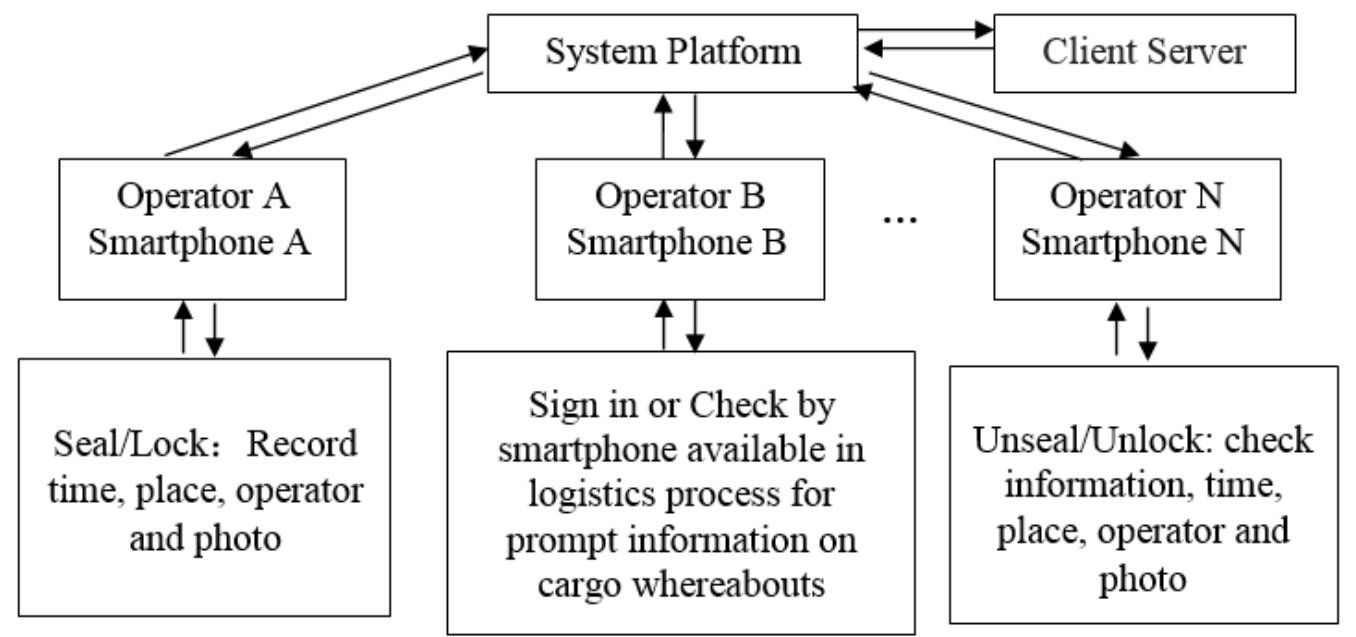

\subsection{E-seal/E-lock}

Fig. 2 Operation procedures of the E-seal/E-lock

E-seal and E-lock are mechanical and electrical integration structure, the similar function make their distinctions obscure, and the concept of key, which is encrypted to data, become virtualization. "Seal" and "unseal", "locking" and "unlocking" are the process of data logging and interaction. The concept of "lock" is no more a complete "functional entity", but an "electromechanical limit function or electromechanical limiter", i.e. the so-called "e-lock" is an e-seal that contains "electromechanical limiter" or a electromechanical equipment with multi - function.

Table 2. The comparison of NFC and BLE technology apply in the seal / lock

\begin{tabular}{|c|c|c|}
\hline Item & NFC & BLE \\
\hline & Passive RFID, $13.56 \mathrm{MHz}$ & Active RFID, 2.4GHz \\
\hline Technical & Communication distance within $5 \mathrm{~cm}$; & Communication distance of $10 \mathrm{~m}$ or less \\
\hline Indicators & Through software to achieve security & Can be achieved security by hardware \\
\hline $\begin{array}{l}\text { Applied to } \\
\text { the e-seal }\end{array}$ & $\begin{array}{l}\text { Electronic structure is simple, no } \\
\text { battery-powered, low costs of } \\
\text { manufacturing and maintenance. }\end{array}$ & $\begin{array}{l}\text { Requires simple circuit and power. supply, } \\
\text { manufacturing and maintenance costs are relatively } \\
\text { high, but can be read remotely, flexible use. }\end{array}$ \\
\hline $\begin{array}{l}\text { Applied to } \\
\text { the e-lock }\end{array}$ & $\begin{array}{l}\text { Communication distance is limited, } \\
\text { must be close to use. Power } \\
\text { consumption is small }\end{array}$ & $\begin{array}{l}\text { Communication distance is far, } \\
\text { But the electricity consumption is larger }\end{array}$ \\
\hline
\end{tabular}

The e-seal / lock, operated by smart phone and mainly adopting the NFC and BLE, can be used according to different applications and needs with respectively advantages. Since NFC is passive, it is very suitable to be applied in seals without equipment maintenance at a lower cost. While for the e-locks, BLE might be a better choice because a $10 \mathrm{~m}$ reading distance makes operation more convenient. But the power consumption is larger than the e-lock based on NFC and need to be charged regularly. The technology comparison is shown in Table 2.

The e-seal has an unchangeable seal number when delivered, and imbedded with the NFC chip holding the exclusive ID number, which cannot be changed and copied. The seal number and the ID number correspondence with each other, so it cannot be counterfeited. As to e-locks, software encryption is the way to guarantee authenticity. NFC e-lock block diagram is shown in figure3. For BLE e-lock structure, the BLE system should replace the NFC system, and the other parts are the same to that of figure 3 . 


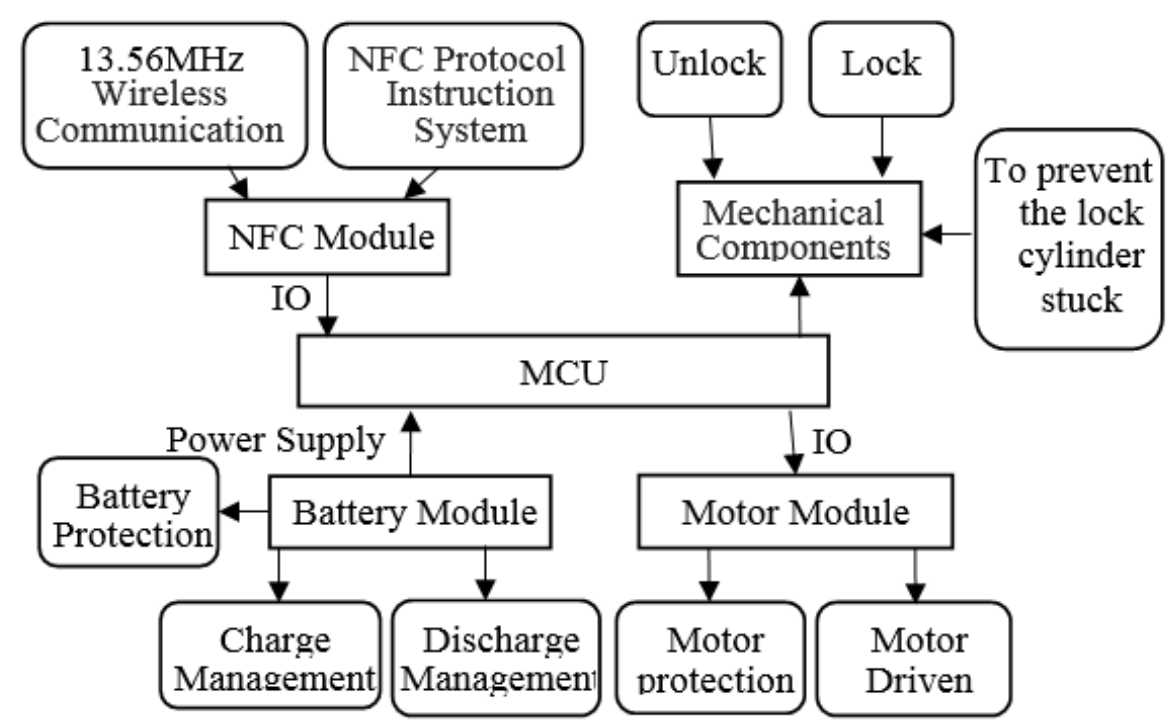

Fig. 3 Structure diagram of E-lock

\subsection{System Platform}

The system platform is a professional independent and open business management information platform. It contains e-seal / lock name resolution, registration management, query and other core parts, providing APP and other network access interfaces. The main functions of the system platform include user information classification management, e-seal / e-lock security certification and management, logistics information storage, global data exchange and synchronization, Electronic lock related query interface etc., shown in Figure 4. The system platform will provides the e-seal / lock related information, including: object with the seal/lock (container number, van license, etc.), the authorized operation time, place, operator, video recording, the operation process of the seal/ lock, mode, status and other information. System platform also provides customers with a full range of logistics information services, through the website, SMS, e-mail, etc.

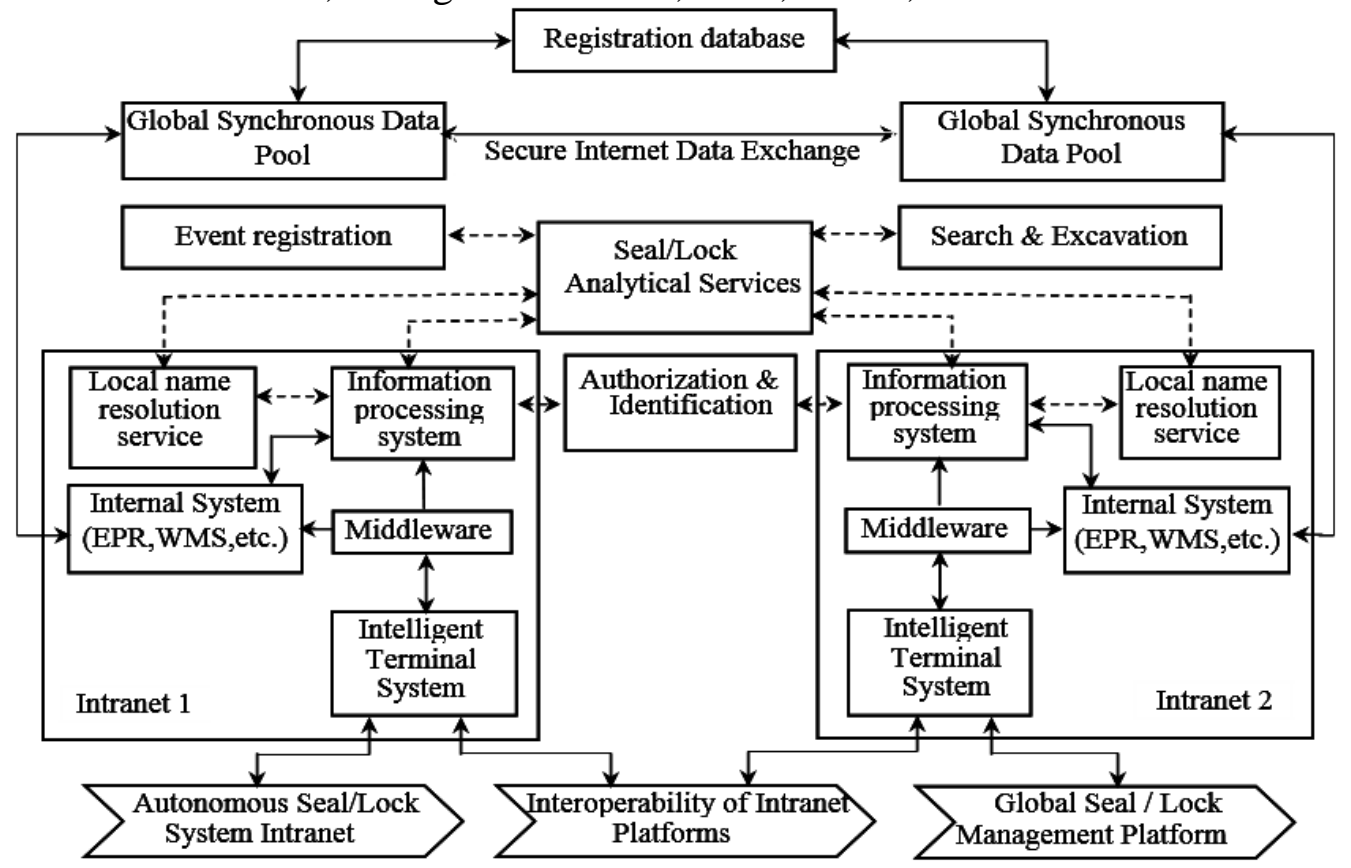

\subsection{APP in Smartphone}

Fig. 4 Functional frame diagram of the system platform

With the functions of mobile communication / WIFI / GPS / camera etc., APP will achieve communication, positioning, video shooting and other functions. APP will also implements other application system client functions, including registration, login, query and so on. Figure 5 is the smart phone APP program flow chart. The first step is user login / registration interface loading. After 
the login, the server will verify the user ID and password, and the APP will obtain the token. The token is valid only in a certain period of time, out of which the login will be expired. When getting the token, APP will load the main interface that uses the TabLayout. There are two Tabs to implement logistics status information query and e-seal / lock operation separately.

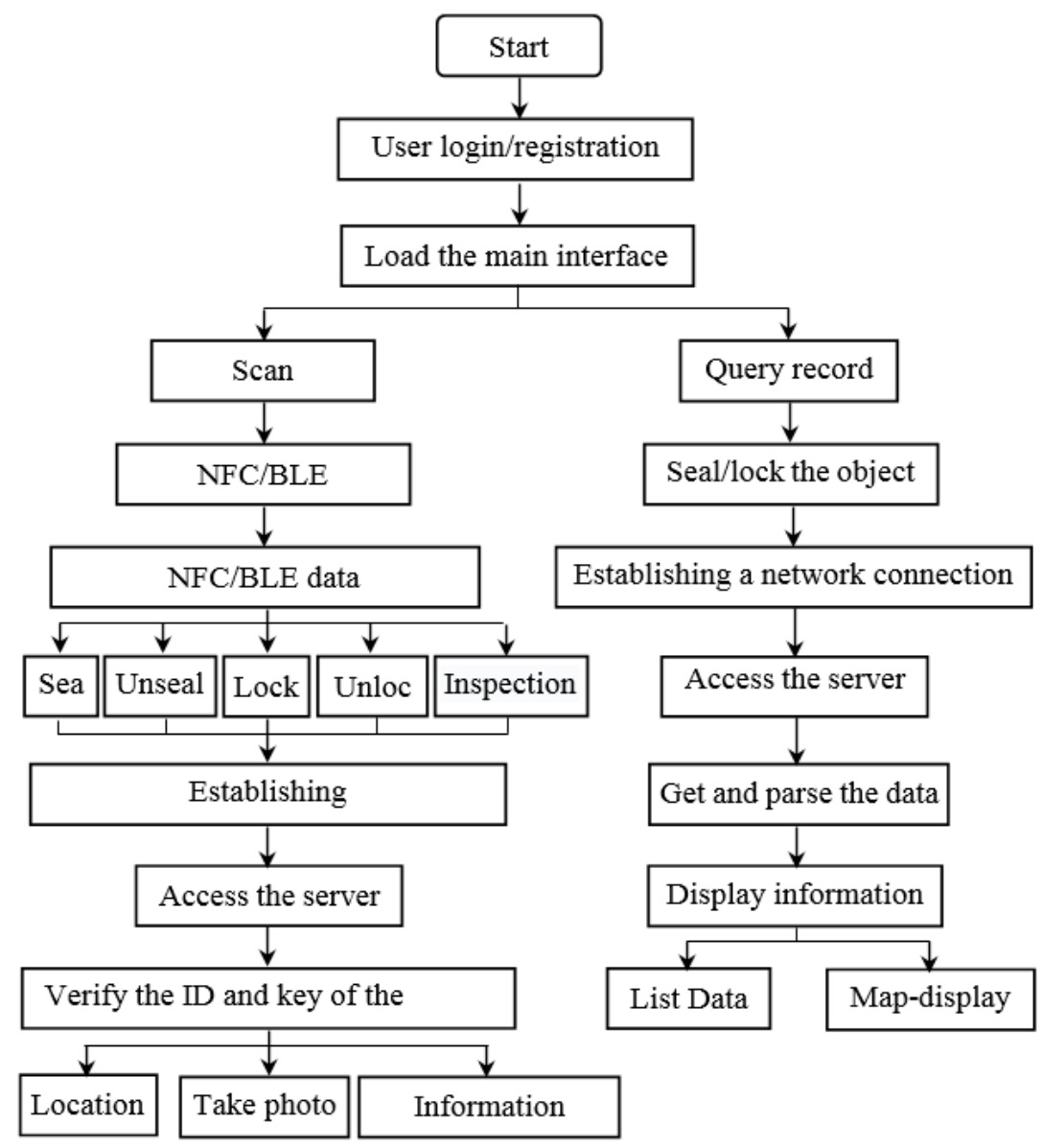

Fig. 5 Program flow chart of the APP

\section{System Functions and Operation}

The system has the following functions: (1)to achieve operational functions of the e-seal / lock such as automatic identification, authenticity identification, access and query through information exchange by smart phone. (2) To control the flow of goods for the user through the node tracking, improving the transparency of logistics. (3) to avoid manual copying by efficient inspection, improving the level of management information. (4) to provide interface that can be integrated to user's ERP system.

Figure 6 is an e-lock mounted on a container. Figure 7 uses the smartphone NFC function to read the e-lock and unlock it. 


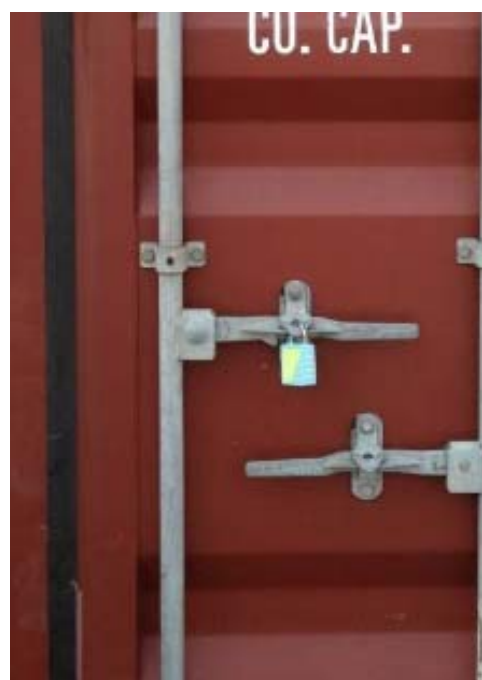

Fig. 6 E-lock

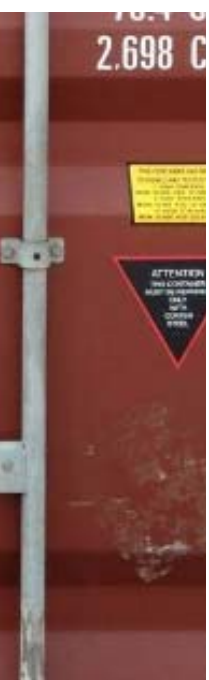

Fig. 7 A smartphone read the NFC e-lock

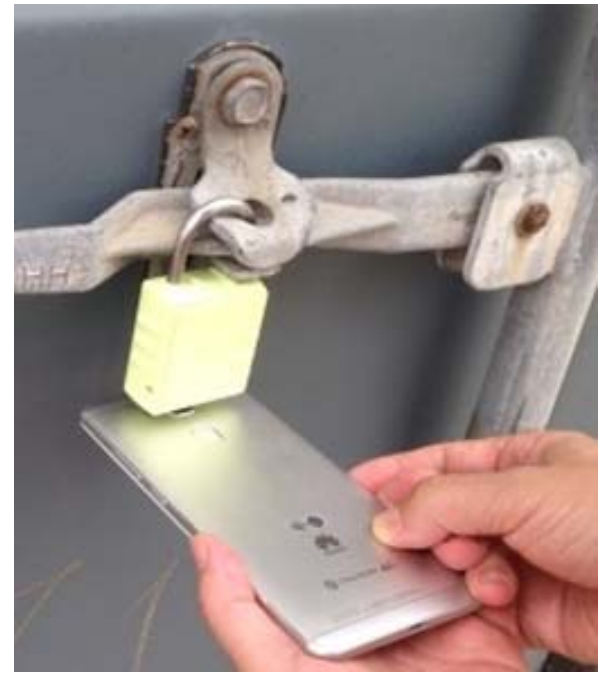

Users can use the APP to conduct operation of seal/unseal, lock/unlock, the location of the target track monitoring, logistics information management. Figure 8(a) is the e-lock function interface. There are two types of e-lock: NFC lock and BLE lock. Figure 8(b) is the NFC e-lock reading interface. The operator need to move the smart phones NFC read area close to the e-lock NFC read area; For BLE e-locks, smart phone will scan and capture the BLE e-lock within about 10 meters range and will access to it according to user's choice. The interface is shown in Figure 8(c).

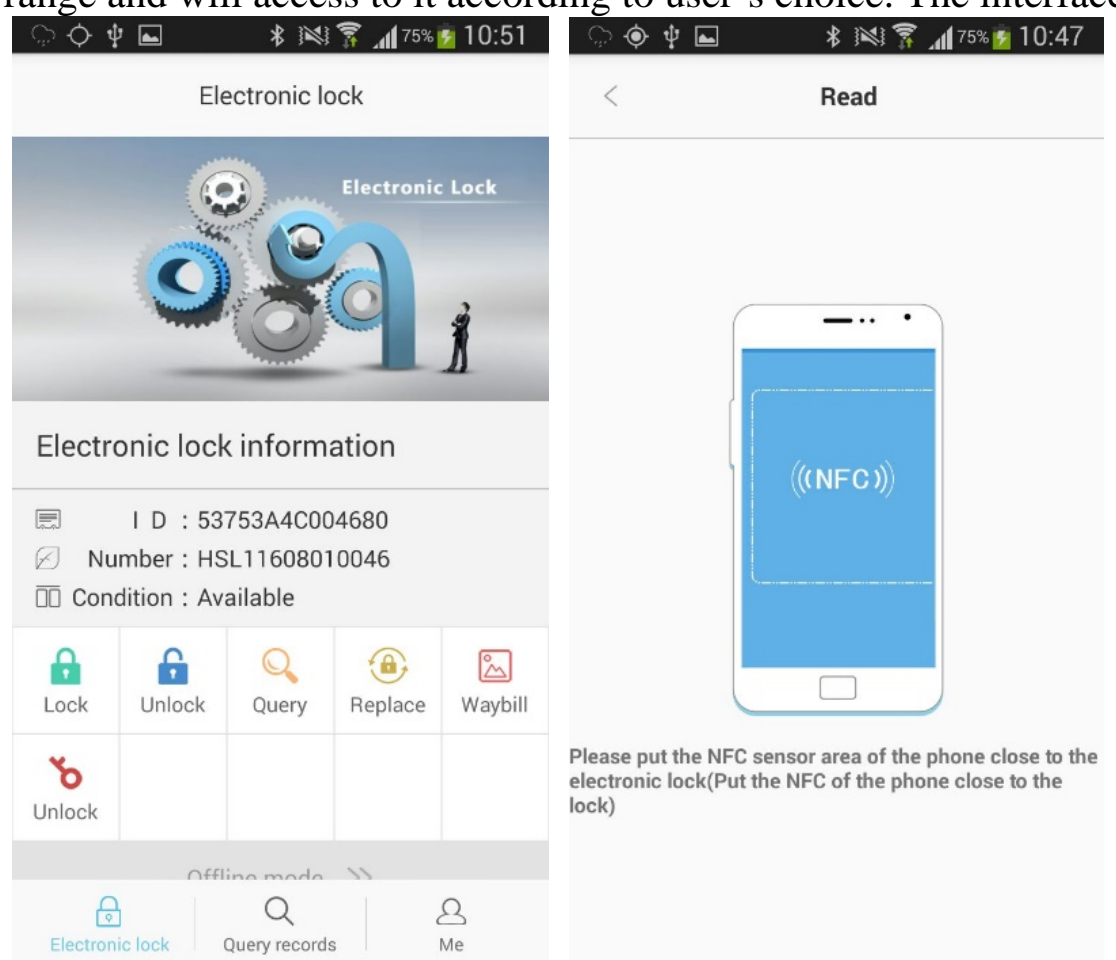

(a)

(b)

Fig. 8 E-lock APP interfaces. (a) E-lock function interface; (b) NFC e-lock reading interface; (c) BLE e-lock reading interface

Take the e-lock trial in Paris, France as an example, see Figure 9(a). Trial time: March 6, 2017. Path: Paris -> Chantilly -> Auvers-sur-Oise -> Paris. See Figure 9(b) and 9(c). It can be seen from figure 9 (b) that the more inspection spots, the more accurate of the track route. 


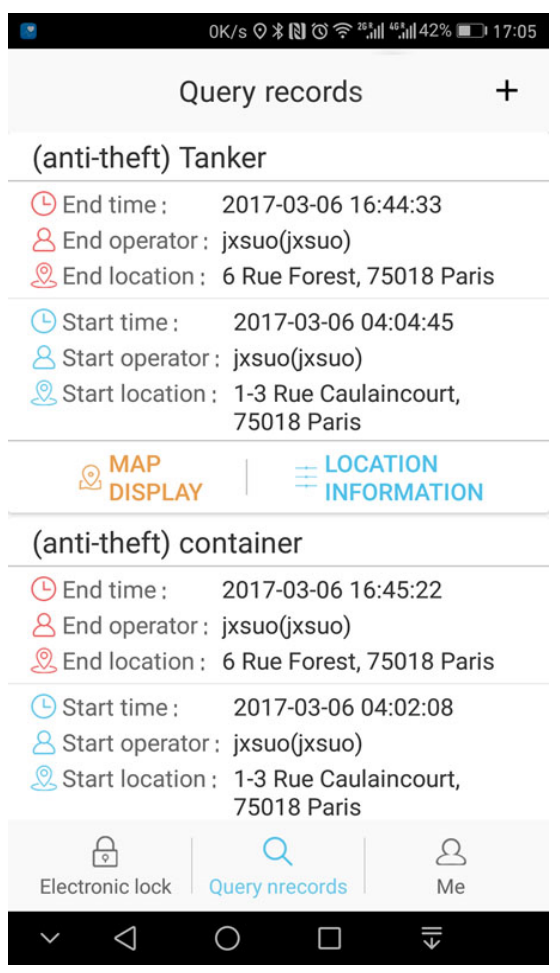

(a)

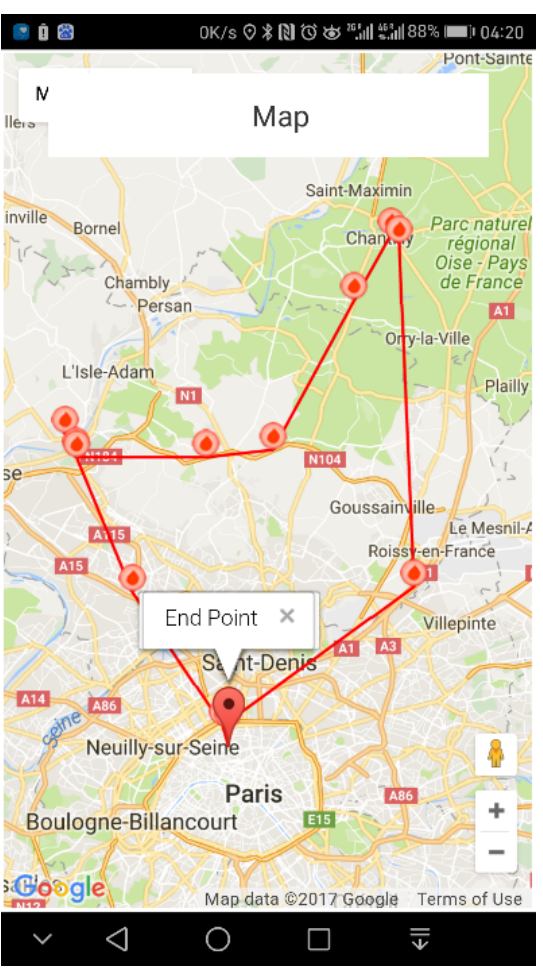

(b)

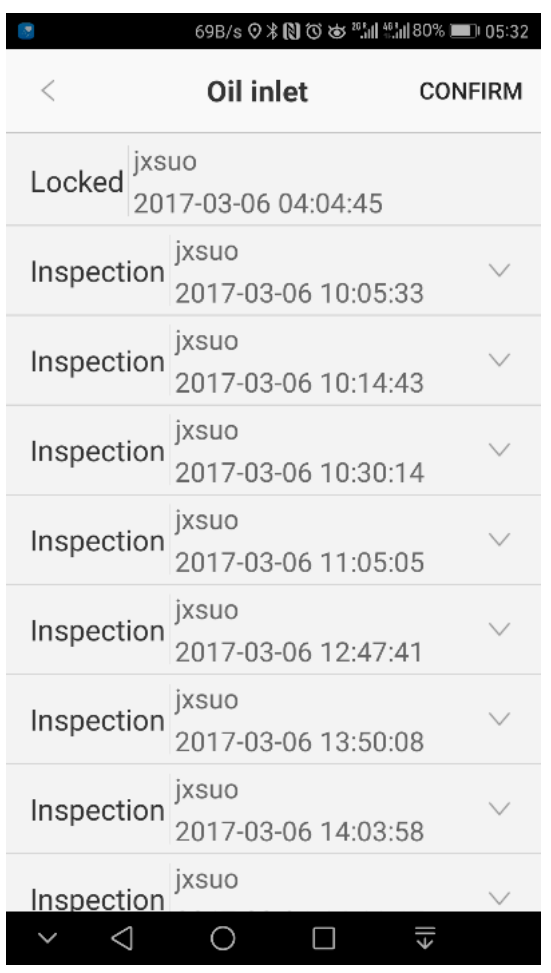

(c)

Fig. 9 Some E-lock query interfaces. (a) Record query; 9(b) Trajectory; 9 (c) Information list of operations

\section{Summary}

At present, the E-seals /E-locks based on mobile internet have been applied in the field of goods security, inspection and quarantine, food transport, petrochemical transport, gas management, etc. in China. Compared to the traditional seals and locks, the importance of E-seals/E-locks are: the concept of "lock" refers to the operation of "sealing" and "unsealing", "lock" and "unlock", during which process electronic signature are required without exception through data recording and interactive, are secured. Especially, violence circumstance is not under the discussion. Permission of the E-locks can be authorized to more than one operators, and the E-locks can be reused. A more complex and more secure management with detailed data can be conducted in the condition of multi-operator.

It is a huge application advantage that the rapid development of Mobile Internet intelligent terminals allows the directly operate to the e-lock, and incorporate the lock management into the information management system.

\section{Acknowledgments}

This work is supported by the Shanghai Science and Technology Achievement Transformation and Industrialization Project (16511103400).

\section{References}

[1]. Dan Burges. Cargo Theft, Loss Prevention, and Supply Chain Security. Elsevier LTD, Oxford, 2012,p.13-33.

[2]. Johan Scholliers, Antti Permala, Sirra Toivonen, et al. Improving the security of containers in port related supply chains. Transportation Research Procedia 14 ( 2016 ) p. 1374 - 1383.

[3]. Ming-Chih Tsai. Constructing a logistics tracking system for preventing smuggling risk of transit containers. Transportation Research Part A 40 (2006) p. 526-536. 
[4]. Francesco Rizzo, Marcello Barboni, Lorenzo Faggion, et al.Improved security for commercial container transports using an innovative active RFID system. Journal of Network and Computer Applications, Volume 34, Issue 3, May 2011, p. 846-852.

[5]. Vladimir Todorovic, Marius Neag, Milovan Lazarevic. On the Usage of RFID Tags for Tracking and Monitoring of Shipped Perishable Goods. Procedia Engineering, Volume 69, 2014, p. 1345-1349.

[6]. Feng-Ming (Chuck) Tsai, Chi-Ming Huang. Cost-Benefit Analysis of Implementing RFID System in Port of Kaohsiung. Procedia - Social and Behavioral Sciences, Volume 57, 9 October 2012, p. 40-46.

[7]. S.H. Choi, B. Yang, H.H. Cheung, et al. RFID tag data processing in manufacturing for track-and-trace anti-counterfeiting. Computers in Industry, Volume 68, April 2015, p. 148-161.

[8]. Igor Bisio, Andrea Sciarrone, Sandro Zappatore. A new asset tracking architecture integrating RFID, Bluetooth Low Energy tags and ad hoc smartphone applications. Pervasive and Mobile Computing, Volume 31, September 2016,p.79-93.

[9]. V Todorovic, M Neag, M Lazarevic. On the Usage of RFID Tags for Tracking and Monitoring of Shipped Perishable Goods. Procedia Engineering, 2014 , 69 (1) , p. 1345-1349.

[10]. I Bisio, A Sciarrone, S Zappatore. A new asset tracking architecture integrating RFID, Bluetooth Low Energy tags and ad hoc smartphone applications. Pervasive \& Mobile Computing, 2016 , 31, p.79-93.

[11]. S Sundaresan, R Doss, S Piramuthu, et al. A secure search protocol for low cost passive RFID tags. Computer Networks. Volume 122, 20 July 2017, p. 70-82.

[12]. AC Bapat, SU Nimbhorkar. Multilevel Secure RFID Based Object Tracking System. Procedia Computer Science. Volume 78, 2016, p. 336-341.

[13]. David R. Gnimpieba Z., Ahmed Nait-Sidi-Moh, David Durand, et al. Using Internet of Things technologies for a collaborative supply chain: Application to tracking of pallets and containers. Procedia Computer Science 56 (2015),p. 550 -557. 